\title{
Pandemia, coyuntura y Trabajo Social
}

\section{Debates urgentes}

Pandemic, conjuncture and Social Work.

Urgent debates

Federico Guzmán Ramonda

Licenciado en Trabajo Social

(Universidad Nacional de Rosario)

Magister en Trabajo Social

(Universidad Federal de Río de Janeiro, Brasil)

Docente e investigador

(Universidad Nacional de Entre Ríos)

Docente

(Universidad Nacional del Litoral)

Correo: federicogr@fts.uner.edu.ar 


\title{
Resumen
}

Las reflexiones que siguen fueron expuestas en la jornada realizada por la Escuela de Trabajo Social de la UNR y el Colegio de Profesionales de Trabajo Social de la 2da. Circunscripción de Santa Fe, el 10 de diciembre de 2020. Se recuperan algunos debates presentes en la escena profesional y que se consideran urgentes y necesarios para desarrollar en el contexto actual.

Palabras clave

Pandemia, Coyuntura, Trabajo Social.

\begin{abstract}
These reflections were firstly exposed in the conference held at the School of Social Work (UNR) and the Professional Association of Social Work of Santa Fe on December 10th, 2020. We recover some professional debates that are considered urgent and necessary to develop in the current context.
\end{abstract}

Keywords

Pandemic, Conjuncture, Social Work. 


\section{La pandemia no es "sujeto": la coyuntura y sus tensiones}

Como expresa Álvaro García Lineras, la actual pandemia del Covid-19 es expresión de los modos de subsunción formal y real de la naturaleza viva a la racionalidad de la producción mercantil, detrás de esta epidemia hay un modo de

(...) definir la riqueza social como ilimitada acumulación privada de dinero y bienes materiales que (...), convierte a la naturaleza, con sus componentes de seres vivos e inanimados, en una simple masa de materia prima susceptible de ser procesada, depredada y financierizada (2020:2).

Al mismo tiempo, esta lógica se viene expandiendo mundialmente a partir del triunfo de un proyecto globalizador con centralidad del capital financiero y desestructuración de los Estados nación, donde el movimiento del capital y las finanzas se liberan progresivamente de todo control político. Se trata de un modo de globalizar la sociedad que "genera más desigualdades e injusticias, debilita los mecanismos de protección y cuidado creados a lo largo de décadas por los diferentes estados nacionales" (2020:2). De modo que la actual pandemia es un acontecimiento mundial que se inscribe en procesos preexistentes, sobre determina y resignifica contradicciones, procesos y conflictos que se vienen desarrollando a escala mundial y nacional. En este sentido, Gatto expresa que la pandemia es la coyuntura de una multiplicidad de conflictos a escala global, "aspecto que suele ser minimizados en proyecciones de expertos (...) que pierden de vista la dimensión constitutiva e inventiva de los conflictos como modos de participación en la morfología de las sociedades en y pos pandemia" (2021:5).

Recuperar el concepto de coyuntura para pensar el impacto de esta pandemia en diferentes campos de la vida social implica otorgarles centralidad a las relaciones de fuerza política (poder y conflicto) como elemento central en la constitución de la realidad, y no mirar las consecuencias de la pandemia como acontecimientos fatales inevitables.

Retamozo y Stoessel (2020) recuperan el concepto de coyuntura afirmando que representa una herramienta teórica central para el análisis político que permite abordar el desafío que tienen las ciencias sociales para 
estudiar el presente. Retoman la reflexión gramsciana sobre el análisis de coyuntura afirmando que este supone articular los movimientos orgánicos con los ocasionales, esto es, en principio, relacionar dos temporalidades para el analizar el presente:

(...) por un lado, la orgánica y estructural-estructurante, esto es, la historicidad de mayor duración. Por otro lado, aquella capa de la historicidad cuyo ritmo está marcado por la temporalidad política y social (...) es aquí importante porque no se trata de dimensiones autónomas sino de una forma de concebir tiempo e historicidad en la política contemporánea (2020:3).

De modo que estudiar la coyuntura representa un estudio del "presente potencial". Así, el estudio de la coyuntura es, en efecto, el análisis del movimiento histórico objetivado, de los procesos, de las relaciones dinámicas entre elementos. El momento coyuntural es aquel corte de tiempo que, lejos de reducir lo posible a lo dado, abre lo dado a las múltiples opciones de proyectos a través de la praxis social, donde "se conjuga lo objetivo, sometido a regularidad, y la capacidad de construir lo objetivamente posible" (2020:3). Delimitar y comprender la coyuntura significa indagar las determinaciones históricas que configuran el presente, la historicidad y, fundamentalmente, los futuros posibles contenidos en nuestro presente a partir recuperar la naturaleza constructora de la praxis social de los sujetos sociales.

En términos generales, no se puede pensar la realidad contemporánea sin comprender el neoliberalismo como una racionalidad política productora de desigualdades y subjetividades o, como expresan Retamozo y Stoessel (2020), neoliberalismo, patriarcado y colonialismo son formas centrales de producción de subjetividades y de desigualdades. Aunque para pensar la particularidad de nuestro tiempo es alumbradora la conceptualización de "neoliberalismo tardío" desarrollada por García Delgado y Gradin (2019), quienes lo caracterizan como el tercer ciclo o tercer momento de la ofensiva de las élites conservadoras y del capitalismo de libre mercado trasnacional, en la disputa por la hegemonía ${ }^{1}$, que encarna plenamente el proyecto político 
de la coalición de derecha Juntos por el Cambio ${ }^{2}$. El Neoliberalismo Tardío como proyecto político representa y expresa un modelo económico, social y geopolítico con características específicas y diferentes a las desarrolladas en las décadas del 1970 y 1990, se expresa de modo general en las políticas de distribución de la riqueza a favor de los sectores concentrados de la economía, por el inicio de un nuevo proceso de endeudamiento externo, la apertura de la economía, la desindustrialización, y la baja de salarios y niveles de consumo de los sectores mayoritarios, como por el alineamiento internacional y geopolítica a los Estados Unidos y los países del norte. Lo distintivo de esta etapa son las subjetividades que se promueven, a partir la exaltación de la cultura liberal e individualista y, donde conjuntamente a la retórica pospolítica, el emprendedurismo se convierte en eslabón central de la construcción de la "hegemonía del proyecto subjetivo del Neoliberalismo Tardío” (García Delgado y Gradin, 2019:18).

Estela Grassi (2019) nos plantea que este proyecto significó un desbloqueo de la sociedad neoliberal, un pasaje de un proyecto político que gobernó el Estado nacional en el período 2003-2015, cuya característica distintiva fue la "reconstrucción del Estado Social”. Este desbloqueo significó no sólo la recomposición de un régimen social de acumulación centrado en el pensamiento económico neoliberal, sino que fortaleció los fundamentos ideológicos que sustentan los ejes estratégicos de un discurso que "despolitiza la cuestión social"’3 y en simultáneo la repolitiza rearmando a esta como un

caracterizada por la disputa entre la corriente popular expansionista y la corriente liberal, por la conducción del proceso de desarrollo en la región. Los ciclos del desarrollo pueden ser explicados a partir de la hegemonía de una corriente sobre otra, primando los intereses de la élite económica sobre los populares en los ciclos neoliberales" (García Delgado y Gradin, 2017:18).

2 La coalición electoral Cambiemos, liderada por Mauricio Macri, se constituyó en la primera fuerza política de derecha que asumió el gobierno nacional por la vía electoral, al vencer a Daniel Scioli en la contienda presidencial de 2015. Cambiemos, en tanto coalición conformada por Propuesta Republicana (PRO), Coalición Cívica (CC) y la Unión Cívica Radical(UCR) y otros partidos menores, se configura como una opción inscripta en la derecha, y, también, emplazada en el eje anti peronista de la topografía política argentina"( Luca e Iglesias, 2019: 9).

3 La reconstrucción de un Estado Social desarrolla por el Kichnerismo "implico la politización de los asuntos públicos y la cuestión social, con eje en la reapreciación simbólica del trabajo, en un contexto en el que la política había vuelto como espacio y como practica que ordena y por la que se expresan las voluntades (sujetos sociales) en conflicto y con diversidad de intereses. En etas condiciones, se reconstruyo la capacidad del Estado en la regulación del trabajo y en la recomposición y extensión de las protecciones y la seguridad social, Loa asuntos que hacen al bienestar fueron construidos como asuntos políticos y 
"campo problemático en términos de miedo, inseguridad, crisis y desorden" (2019:61).

Siguiendo a Campana Alabarce (2019), podemos afirmar que el gobierno de la Alianza Cambiemos significó, con respecto a la cuestión social, un declive de las protecciones sociales público-estatales que se expresa en cuatro grandes tendencias o desplazamientos: del derecho a la protección a la posibilidad de crédito; del colectivo al individuo; de la igualdad a la equidad; y de la ciudadanía a la meritocracia. Estas cuatro tendencias se van materializando a partir de tecnologías de intervención ya que "gobernar es producir": como nos recuerda Giavedoni (2018), se gobierna algo que debe ser previamente constituido en problema gobernable pensado, caracterizado, tipologizado. A grosso modo, podemos decir que con el gobierno de Cambiemos se pasa de una racionalidad de gobierno welfarista a otra neoliberal donde se contraponen tecnologías de intervención diferentes:

(...) en una la sociedad es el objeto a proteger y en la otra es el individuo: en aquella a través de sistemas de seguridad social, protección colectiva al trabajo, sistemas de educación pública, de salud pública, de vivienda pública; en la segunda el sistema es individual, de capitalización individual, a través de créditos, de seguros individuales" (Giavedoni, 2018:36).

La derrota electoral de la Alianza Cambiemos y el acceso al gobierno por parte de la coalición Frente de Todos, expresa el conflicto de proyectos que caracteriza la coyuntura vigente abriendo un nuevo tiempo político determinado por el desarrollo de una pandemia mundial. Entonces, "pandemia no es sujeto", antes bien debe considerarse el actual proceso como un escenario particular donde se aceleran procesos y tendencias prexistentes y donde se procesan los conflictos políticos que atraviesan nuestra sociedad.

El análisis de esta coyuntura se presenta como una necesidad del pensar situado, ya que representa el suelo histórico concreto que le otorga par-

de política que redefinían los ámbitos de responsabilidad y delimitaban las obligaciones desde y para el propio Estado (Grassi, 2019: 114).

4 Afirmación realizada por Ana Arias en una conferencia organizada por el colegio de graduados y profesionales de CABA. 
ticularidad a nuestros problemas y desafíos. Este contexto, como expresa Cazzaniga (2019), opera de modo constitutivo sobre la intervención social y profesional: estos siempre expresan las relaciones de fuerza y las luchas de poder por el sentido de los proyectos políticos, proyectos que se vinculan a los proyecto profesionales, de modo que conocer y comprender el contexto se convierte en condición de posibilidad para que las intervenciones profesionales tengan viabilidad, densidad histórica, y más aún "conocerlo y comprenderlo como producto de la historia política se convierte en un imperativo ético" (Cazzaniga, 2019:3).

\section{Debates y combates}

Ante esta situación marcada por un proceso de declive de las protecciones sociales público-estatales que se desarrolló durante el macrismo, el inicio de un nuevo gobierno con un programa político diferente a la coalición de derecha y ante la situación de emergencia que genera la pandemia, el Trabajo Social a partir de múltiples y variadas experiencias y expresando sus diferentes tendencias se constituye en un actor que participa del debate en el espacio público sobre los problemas, conflictos y desafíos que esta situación presenta para la intervención social y profesional. A partir de visibilizar la profundización de diferentes problemas sociales que expresan el proceso de profundización de las desigualdades, analizar el impacto de la pandemia en campos de intervención específicos, visibilizando nuevas conflictividades el Trabajo Social, participa activamente de las disputas por la hegemonía, por la producción de sentido, siendo protagonista lo que Grassi (2019) denomina como procesos de reflexividad política cultural a partir de los cuales la sociedad desarrolla discursos donde se juega la legitimidad de los sistema institucionales particularmente "los sistemas seguridad social y asistencia social" y "las políticas sociales" que constituyen el entramado complejo de que funcionan como soporte de la existencia de los individuos 5 .

5 "No hay vida posible sino se desarrolla en un marco de soportes institucionales que se inscriban más allá de la familia. En este marco se entiende la inscripción de la política social y su centralidad en la definición de las condiciones de vida colectiva: no solo la de los pobres y desamparados, sino del conjunto de la población (y de la del diverso mundo del trabajo, principalmente) que soporta la vida social y el "ser 
Dentro de este proceso de crónica, denuncia, visibilización, estudio y desarrollo de imaginación política que se desenvuelve, el Trabajo Social ante la situación de incertidumbre expresa sus múltiples crisis que golpean y devoran sobre todo a los "condenados de la tierra", y considerando que los futuros posibles se juegan y entretejen en los conflictos actuales, recupero dos debates, dos propuestas que considero estratégicas para transitar esta crisis politizando los problemas que enfrentamos en nuestra intervención, iniciativas que expresan diferentes escalas pero que se articulan. Las mismas nos ofrecen un horizonte de construcción de una sociedad más justa y solidaria que puede adquirir densidad histórica si somos parte de la construcción de una hegemonía política, es decir de una nueva voluntad colectiva nacional popular.

\section{El regreso del Estado, ¿de qué Estado?}

Como expresan múltiples discursos, asistimos a una revalorización del Estado, de su función social protectora ante los efectos de la pandemia, como económico financiera. Este "retorno" del Estado, como analiza García Linera (2020) en términos globales, se desarrolla a partir de dos grandes tendencias: por un lado, pensar el rol de Estado bajo la forma de un "keynesianismo invertido y de un totalitarismo del big data como novísima tecnología de contención de las "clases peligrosas" (2020:4) ${ }^{6}$. Esta forma de pensar el Estado supone la utilización del dinero público, para sostener las tasas de rentabilidad de las grandes corporaciones, y representa no un "Estado social protector, sino patrimonializado por una aristocracia de los negocios” (2020:4), lo que significa la profundización del proyecto neolibe-

individuo". Aún más ser individuo-individualista se sostiene en instituciones (y aún en políticas sociales) que pueden presentar y reproducir la idea de un individuo radicalmente autosuficiente como una aspiración y una conquista" (Grassi,2019:19).

6 Como anticipa Lineras (2020) "el uso del big data es irradiado desde el cuidado médico de la sociedad a la contrainsurgencia social, estaremos ante una nueva fase de la biopolítica devenida ahora en data-política, que de la gestión disciplinaria de la vida en fábricas, centros de reclusión y sistemas de salud pública, pasa al control algorítmico de la totalidad de los actos de vida, comenzando por la historia de sus desplazamientos, relaciones, elecciones personales, gustos, pensamientos y hasta de sus probables acciones futuras, convertido ahora en datos de algún algoritmo que "mide" la "peligrosidad" de las personas; hoy, peligrosidad médica; mañana, peligrosidad cultural; pasado, peligrosidad política” (2020:5). 
ral. Por otro lado, expresa que no es posible un retorno idéntico a formas del Estado de bienestar o desarrollista de décadas anteriores ya que existen a nivel global "unas interdependencias técnico-económicas que ya no pueden retroceder para erigir sociedades autocentradas en el mercado interno y el asalariamiento regular" (2020:4). García Linera considera necesario que las formas emergentes de Estado combinen

(...) una revalorización del mercado interno, la protección social ampliada a asalariados, no asalariados y formas híbridas de trabajo autónomo, profundas políticas de democratización de la propiedad y las decisiones sobre el futuro, con la articulación controlada de las distintas cadenas de suministros mundiales, la fiscalización radical de los flujos financieros e inmediatas acciones de protección del medioambiente planetario (2020:4).

Dentro del horizonte que abre esta segunda perspectiva, se encuentran las posiciones de diferentes referentes de nuestra profesión como Estela Grassi, Ana Arias y Susana Cazzaniga, entre otras, quienes plantean que se hace necesario fortalecer la presencia del Estado en la intervención sobre los problemas que genera la pandemia al mismo tiempo que trabajadores sociales debemos problematizar qué tipo Estado se está consolidando, coincidiendo en que tenemos imaginar y aportar a construir un nuevo Estado que repare, garantice y profundice derechos.

Este debate teórico político es urgente y, si bien excede ampliamente a nuestra profesión, desde el Trabajo Social a partir de la dependencia estructural que se constituyó históricamente entre las instituciones estatales y la intervención profesional, podemos aportar a la elaboración de un pensamiento que permita habitar el Estado en este tiempo para construir un proyecto colectivo, una voluntad colectiva nacional y popular contrahegemónica que exprese intereses y anhelos de los sectores subalternos. Es importante marcar que este debate se sitúa dentro de una tendencia general caracterizada por la pérdida de centralidad del Estado en la producción de sociedad. Como indican Abad y Cantarelli (2013), este proceso que se desarrolla a escala global se vincula a la desarticulación de la institución Estado de Bienestar, que en nuestro país se inicia con fuerza a partir de la última dictadura 
cívico militar (1976-1983) y que hace referencia al proceso de transformación del Estado y sus instituciones. La pérdida de centralidad hace referencia a la reducción de aspectos cuantitativos y cualitativos a partir de los cuales el Estado dentro del territorio articula y produce subjetividades, lazo social, y emergen otras fuerzas que disputan el poder del Estado e impugnan su carácter representativo ocupando una posición de centralidad social: las corporaciones financieras y de comunicación son ejemplo de estos poderes. Esta situación es central para analizar las relaciones de fuerza e identificar, siguiendo a Argumedo (1996), cómo se combinan las principales instancias de poder que se expresan dentro de una sociedad dentro de un escenario internacional y en una etapa histórica determinada, detentadas por uno u otro de los grandes proyectos políticos enfrentados ${ }^{7}$.

Considero centrales los aportes que viene realizando Ana Arias (2014, 2015, 2020) desde nuestra profesión sobre el debate del Estado y la construcción de una nueva estatalidad. Cuando reconoce el debate que existe en nuestras tradiciones críticas sobre este tema, expresando que hay "tradiciones críticas [que] parecen más entrenadas para realizar acciones alternativas a los procesos institucionales públicos que para leer procesos en los que el Estado debe recuperar capacidad para institucionalizar su intervención" $(\text { Arias, 2015:162) })^{8}$. En la perspectiva de Arias, la construcción de una nueva

7 Argumedo (1996) establece que las más importantes manifestaciones contemporáneas de ese poder son: "el poder militar, como capacidad real o potencial del ejercicio de la violencia, en diferentes niveles; el poder económico en tanto propiedad y control de los medios de producción, financieros, de comercialización interna y externa; el poder derivado de la capacidad de gestión, de decisión y utilización de los recursos tecnológicos de carácter estratégicos; el poder de las comunicaciones e información como instrumentos de poder que ha adquirido un papel decisivo en las últimas décadas debido a la expansión de las comunicaciones y procesos tele-informáticos. El poder de la representatividad social lo político cultural, que se manifiesta en la capacidad de gestar consensos y hegemonías en la sociedad civil como en el control del aparato estatal; (...) En el interior de las sociedades, este poder de representatividad se desagrega en formas institucionales (iglesias, sindicatos, movimientos políticos y sociales) o entidades sociales no necesariamente organizadas (étnicas, religiosas, culturales) más allá del grado de estructuración que los diferentes sectores hayan alcanzado en cada coyuntura" (1996:231).

8 El debate que sitúa Arias protagonizadas por las diferentes perspectivas teóricas y políticas de la tradición crítica profesional, expresan las grandes tendencias, que reconstruyen Castellani y Sowter (2016) que se desarrollan en el campo critico de las ciencias sociales que abordan este tema, donde se encuentran quienes fundamentan que el Estado nacional ocupa un lugar primordial en el desarrollo de las luchas emancipatorias constituyendo el espacio central "desde el cual construir una alternativa "emancipatoria" respecto de las fuerzas del capital transnacional”(2016:56) y otres que afirman que el Estado procesa demandas y conflictos solo para garantizar "el mantenimiento de un orden social capitalista" (2016:60). 
estatalidad se asocia a la vigencia y avance de proyectos nacionales y populares que puedan construir estados fuertemente intervencionistas que se constituyan como "espacio de concreción de política", para construir una "institucionalidad pública estatal -no siempre tradicional-, como ámbito de resolución de problemas como la distribución de la riqueza" (2015:161), donde el Estado ocupe un lugar central de direccionador de una ingeniería social. Esta tarea demanda no solo reinventar la institucionalidad del Estado sino recrear la alianza político social que lo sostiene. Construir una nueva estatalidad en esta perspectiva tiene como objetivo poder efectivizar derechos, estableciendo normas, miradas, conocimientos, servicios que "logren instituir nuevas formas de relación nuestros problemas sociales" (Arias, 2014:11) y expresar en el terreno histórico concreto la articulación de un bloque contra-hegemónico. La perspectiva de la autora dialoga con aquellas lecturas que no ven al Estado como una entidad monolítica que reproduce unívocamente los intereses de clases o sectores determinados. Antes bien, reconoce el carácter contradictorio y conflictivo que se desarrollan en las diverso y heterogéneo mundo institucional del Estado donde "la unidad relativa del poder del Estado es fruto de un movimiento contradictorio que no se establece a priori" (Coutinho, 2011:40). Entonces su institucionalidad es susceptible de tornarse espacio donde instituir y profundizar derechos, haciendo sociedad a partir de revalorizar la solidaridad y la construcción de lo común como instancias para producir sujetos, subjetividades y profundizar procesos de poder popular. Como expresa Aricó (1985) las clases subalternas no están unificadas y no pueden unificarse hasta que no se vuelvan Estado: "estas se van construyendo en su propio proceso de devenir Estado, o sea fuerza hegemónica” (1985:13).

En esta perspectiva, el Estado es un momento, una dimensión central del proceso de emancipación de construcción de nuevos lazos sociales. 


\section{La asistencia como derecho}

La propuesta de lograr una Ley Nacional de Asistencia Social, impulsada por la Red Argentina de Investigación sobre Asistencia Social (RAIAS) ${ }^{9}$, representa un proyecto concreto para construir una estatalidad que brinde respuesta en términos de derechos y justicia social ante una situación estructural que se desarrolló y consolidó con el desenvolvimiento del neoliberalismo en nuestro país. Como estudia Svampa (2005), la metamorfosis neoliberal de la sociedad argentina implicó una desregulación económica como una restructuración del Estado, que mediante procesos de descolectivización e individuación de lo social provocaron una gran mutación en nuestra sociedad profundizando y acrecentando las desigualdades, generando una dinámica de fragmentación en las clases medias y un proceso de pauperización y territorialización de las clases populares. El principal resultado de esta tragedia significó, como lo define Campana Alabarce (2019), la consolidación de grandes contingentes poblacionales precarios, colocados en el centro de la organización social y no en sus márgenes a partir la necesidad y la demanda de producción de población precaria en esta etapa del capitalismo. Esta población se constituye en sobrante para la racionalidad de la producción capitalista. Por este motivo, es necesario pensar formas de inclusión e inscripción en la sociedad de estas poblaciones que vayan más allá del trabajo formal, construyendo formas de acceso a un nivel de vida digna por el sólo hecho de ser ciudadanos. Esto implica poner el debate en la producción y orígenes de la desigualdad sobre causas históricas y no naturales e individuales, como desarrollar una la batalla por el derecho a la asistencia (no residual y episódica).

En este plano, las impulsoras de esta propuesta tienen en claro que desarrollar la misma significa construir hegemonía para reformar el Estado, construir derecho humano inalienable, capaz de restituir la justicia social que nuestro pueblo reclama y merece. El proyecto parte de desarrollar grandes discusiones urgentes en esta coyuntura: por un lado, reconocer el carácter 
histórico y relacional de la desigualdad y la pobreza y no pensar la misma como un problema individual. Esto interpela de lleno en el sentido común producido por los proyectos y la racionalidad neoliberal, pero también supone debatir con lo que se conceptualiza como "matriz trabajo céntrica" que ha predominado en los proyectos políticos de corte nacional y popular, ya que institucionalizar la asistencia como propone este proyecto implica colocar un signo de interrogación en torno a la posibilidad de la inclusión a través del gran ordenador social que ha sido el trabajo formal asalariado.

Este proyecto propone transformar las políticas asistenciales y terminar con el carácter residual, estigmatizante e institucionalmente débil, volátil y fragmentado con el que se las pensó históricamente para "situar la Asistencia Social dentro del Sistema Público Estatal de Protección Social. Nos referimos con ello al sistema integrado por los subsistemas de salud, de educación, de seguridad social y de Asistencia Social” (RAIAS, 2019:8). De modo que la Asistencia Social se instituya en un sistema conformado por servicios, prestaciones y normativas "cuya finalidad principal es la atención, promoción y desarrollo pleno de todos los miembros de la sociedad, para la obtención de su mayor bienestar, a través de acciones destinadas a atender, prevenir y eliminar las causas que conducen a situaciones de precariedad social" (RAIAS, 2019:8). Esta transformación institucional se fundamenta en permitir niveles de vida digna por el sólo hecho de ser ciudadanos, y en profundizar la democracia pensada como como proceso, lo que supone trabajar la idea de democratizar y "desarmar las aporías que habitan en la idea de que la democracia implica no tocar los privilegios de los sectores concentrados, y habilitar discursos que legitimen la idea de que donde hay una necesidad nace un derecho" (RAIAS, 2019:11).

Instituir una Ley Nacional de Asistencia Social supone construir legitimidad para su sanción como norma, como también deconstruir las prácticas instituidas de los dispositivos que tendrán a su cargo la implementación de la misma. Como lo consideran sus impulsoras, pensar una ley de este tipo implica "des-colonizar instituciones, programas de formación de los cuadros técnicos y profesionales, revisión y transformación de protocolos, normas, 
circuitos administrativos, deconstrucción de universos simbólicos muy pesados, atiborrados de imaginarios racistas y patriarcales" (RAIAS, 2019:10).

Por todo lo expuesto, considero ambos debates y propuestas sobre cómo nuestras intervenciones sociales y profesionales tienen como objeto construir otra institucionalidad estatal como la propuesta de una ley que refunda la asistencia y su institucionalidad desarrolla por Red Argentina de Investigación sobre Asistencia Social, deben ser banderas e iniciativas impulsadas por las diferentes instituciones que componen el colectivo profesional de modo de construir viabilidad para obtener efectividad y concreción de las mismas en la actual coyuntura.

\section{Referencias bibliográficas}

Abad, Sebastián y Cantarelli, Mariana (2013). Habitar el Estado. Pensamiento estatal en tiempos a-estatales. Ciudad de Buenos Aires, Argenitna, Editorial HYDRA.

Arias, Ana Josefina (2020). El problema del triángulo del trabajo Social e Instituciones en una propuesta del CELATS. Escenarios de Trabajo Social y Ciencias Sociales, (31). https: / revistas. unlp.edu.ar/escenarios/article/view/10037/8775

Arias, Ana Josefina (2015). "El trabajo Social desde el Pensamiento Nacional y Popular". En P. Meschini y M. E. Hermida (Ed.), Hacia una Epistemología de los problemas sociales Latinoamericanos. La Plata, Argentina, UNLP.

Arias, Ana Josefina (2014). "Instituciones y Trabajo Social. Preocupaciones para construir lo público". En: A. J. Arias, B. García Godoy y R. Manes (Eds.), Debates en torno a la construcción de la institucionalidad. Aportes para la reconstrucción de lo público. Buenos Aires, Argentina, Espacio.

Argumedo, Alcira (1996). Los Silencios y las voces en América Latina. Notas sobre el pensamiento nacional y popular. Buenos Aires, Argentina, Ediciones del pensamiento nacional y popular.

Campana Alabarce, Melisa (2019). “¿Pobreza Cero? El deterioro del sistema público estatal de protecciones sociales en la Argentina de Cambiemos”. En E. Iglesias y J. B. Lucca (Eds.), La Argentina de Cambiemos. Rosario, Argentina, UNR Editora.

Campana Alabarce, Melisa (2017). Neoliberalismo y precariedad. Aportes para su problematizar la intervención. Conferencia desarrollada en el V Seminario Internacional "Palabras y Cosas del Trabajo Social”. Universidad Alberto Hurtado. Santiago de Chile. 12 de octubre.

Castellani, Ana y Sowter, Leandro (2016). "Estudios sobre el Estado en la sociedad contemporánea". En S. Barrios et. al. (Eds.), Estudios sobre estado, gobierno y administración pública en la Argentina contemporánea. Ciudad Autónoma de Buenos Aires, Argentina, CLACSO.

Cazzaniga, Susana (2019). Problemáticas del desborde. Reconfiguraciones y desafios para el trabajo social. Paraná, Argentina, Mimeo.

Coutinho, Carlos Nelson (2011). Marxismo e politica. La dualidad de poderes y otros ensayos. Santiago de Chile, Chile, LOM Ediciones. 
Gatto, Ezequiel (2021). A partir de la pandemia. Le Monde Diplomatique, (263). https://www. eldiplo.org/263-pandemia-perpetua/a-partir-de-la-pandemia/

García Lineras, Álvaro (2020). Conferencia Inaugural. Ciclo académico de las carreras de Sociología y Antropología del Instituto de Altos Estudios Sociales de la Universidad Nacional de San Martin. Buenos Aires, Argentina.

García Delgado, Daniel y Gradin, Agustina (2017). Neoliberalismo tardío: entre la Hegemonía y la inviabilidad. El cambio de ciclo en la Argentina. Ciudad autónoma de Buenos Aires, Flacso Argentina.

Iglesias, Esteban y Lucca, Juan (2019). Introducción. "En la Argentina de Cambiemos". En E. Iglesias y J. B. Lucca (Eds.), La Argentina de Cambiemos. Rosario, Argentina, UNR Editora.

Giavedoni, José (2018). El Neoliberalismo y sus modos de regulación social. Crisis, empresa y competencia. Revista Perspectivas Sociales/ Social Perspectives, 20(2), 31-62. https://perspectivassociales.uanl.mx/index.php/pers/article/view/74/43

Grassi, Estela e Hintze, Susana (2019). Tramas de la desigualdad. Las politicas y el bienestar en disputa. Buenos Aires, Argentina, Prometeo.

Retamozo, Martín y Stoessel, Soledad (2020). Neoliberalismo, democracia y subjetividad: el pueblo como fundamento, estrategia y proyecto. REVCOM Revista cientifica de la red de carreras de Comunicación Social, (10). http://sedici.unlp.edu.ar/handle/10915/107809

RAIAS (Red Argentina de Investigación sobre Asistencia Social) (2019). Documento de trabajo $n^{\circ}$ 1: por una Ley Federal de Servicios Socio Asistenciales: consideraciones históricas, epistémicas y estratégicas. Mar del Plata, Argentina. Recuperado de: http://tssantafesur.org.ar/wp-content/ uploads/2020/01/RAIAS-DocumentodeTrabajoN $\%$ C2\%BA1-2019-1.pdf

Recibido: $16 / 4 / 2021$

Aceptado: 7/6/2021 